\title{
Patients with Cardiorenal Syndrome Revealed Increased Neurohormonal Activity, Tubular and Myocardial Damage Compared to Heart Failure Patients with Preserved Renal Function
}

\author{
Alberto Palazzuolia Gaetano Ruocco ${ }^{a}$ Marco Pellegrinia \\ Simona Martini ${ }^{b} \quad$ Gabriele Del Castillo $^{a}$ Matteo Beltrami ${ }^{a}$ \\ Beatrice Franci ${ }^{a}$ Barbara Lucani ${ }^{a}$ Ranuccio Nuti ${ }^{a}$ \\ ${ }^{a}$ Cardiology Unit, Department of Internal Medicine, University of Siena, and ${ }^{b} \cup O$ Chemical \\ Laboratory, Le Scotte Hospital, Siena, Italy
}

\section{Key Words}

Heart failure $\cdot$ Cardiorenal syndrome $\cdot$ Renal function $\cdot$ Biomarkers

\begin{abstract}
Background: Cardiorenal syndrome (CRS) is associated with increased cardiovascular morbidity and mortality; still, its biomarker pattern has been poorly evaluated so far. The aim of this study was to measure the inflammatory activation, neurohormonal status and kidney and myocardial damage in patients with CRS compared to patients with heart failure (HF) without renal impairment (RI). Methods: We analyzed 246 patients on the basis of renal function (group 1: $120 \mathrm{HF}$ patients without RI; group 2: 126 CRS patients). In each group, interleukin-6, tumor necrosis factor- $\alpha$, B-type natriuretic peptide (BNP), neutrophil gelatinase-associated lipocalin (NGAL), troponin T (TnT), osteoprotegerin and blood urea nitrogen (BUN) were measured. The diagnostic power of all laboratory parameters to detect CRS was evaluated by the receiver operating characteristic (ROC) curve and logistic regression analysis. Results: A significant increase in BNP $[626.4 \mathrm{pg} / \mathrm{ml}$, confidence interval (CI) $518-749$ vs. $487.8 \mathrm{pg} / \mathrm{ml}, \mathrm{CI}$ 411-578; $p$ < 0.05], NGAL (156 ng/ml, CI 129-186 vs. 89.1 ng/ml, CI 72-109; $p<0.0001)$, BUN (108.9 mg/dl, CI 98-120 vs. $51 \mathrm{mg} / \mathrm{dl}, \mathrm{CI} 46-55 ; \mathrm{p}<0,0001)$ and TnT (0.62 ng/ml, CI 0.51-0.75 vs. $0.21 \mathrm{ng} / \mathrm{ml}, \mathrm{CI} 0.15-0.28 ; \mathrm{p}<0.001$ ) was seen in CRS patients compared to HF patients without RI. ROC curve analysis showed that only NGAL, BUN, BUN/creatinine ratio and TnT can discriminate patients with CRS from patients without RI. Conclusions: In CRS patients, renal tubular damage and neurohormonal and cardiac injury activation are increased compared to patients without RI. The current biomarker pattern could be used for an early diagnosis of RI in acute and chronic HF.




\section{CardioRenal Medicine}

\begin{tabular}{l|l}
\hline Cardiorenal Med 2014;4:257-268 \\
\hline DOI: 10.1159/000368375 & $\begin{array}{l}\text { @ 2014 S. Karger AG, Basel } \\
\text { www.karger.com/crm }\end{array}$ \\
\hline
\end{tabular}

Palazzuoli et al.: Biomarkers of Cardiorenal Syndrome

\section{Introduction}

Impaired renal function has consistently been proven to be an independent risk factor for adverse outcome in patients with heart failure (HF). Renal impairment (RI) is one of the most common associated diseases in HF patients, and it has been increasingly recognized as an independent risk factor for morbidity and mortality [1]. Recent trials have demonstrated that about $40 \%$ of patients hospitalized for HF showed an increase in their serum creatinine and a decrease in their glomerular filtration rate (GFR) [2, 3]. A definition of cardiorenal syndrome (CRS) has recently been reported in an academic way, stressing the bidirectional concept that HF has numerous negative effects on kidney function. This classification includes three principal factors: HF, renal dysfunction and fluid overload. All of these elements could potentially contribute in different ways and phases to maintain and amplify the syndrome [4]. Together with the hemodynamic mechanisms, there are several factors that are involved in the pathophysiological process: neurohormonal and inflammatory mediators are often elevated, leading to endothelial dysfunction and a progression of atherosclerosis $[5,6]$. Promoters of calcification are increased and inhibitors of calcification are reduced, resulting in vascular injury associated with end-stage renal disease. The majority of these traditional and new risk factors have been poorly investigated, and their exact clinical impact on CRS and $\mathrm{HF}$ is still unclear. A better assessment of laboratory biomarkers such as congestion, neuroendocrine activation, primitive kidney-cardiac damage and inflammatory activation could lead to a better comprehension of the cardiorenal relationship [7, 8]. Moreover, creatinine and GFR levels are two parameters currently employed with excellent sensitivity, but unfortunately they cannot identify the exact nature of the mechanisms involved. They are both biomarkers of late renal damage and are ineffective in recognizing RI during the early stages as well as the exact nature of the kidney injury (tubular or glomerular damage). Although a number of 'interesting' risk markers have been proposed as providing additional prognostic information on HF and associated chronic kidney disease (CKD), a precise laboratory cutoff and biomarker pattern able to recognize CRS patients has not been reported yet [9]. Therefore, influential authors have proposed some algorithm to better recognize patients with a change in renal function during their hospitalization in order to identify those with a poor outcome. For all these reasons, we retrospectively studied patients affected by CRS and patients affected by HF with preserved renal function, categorizing them on the basis of the GFR cutoff $[2,10]$. We analyzed markers of inflammation, vascular calcification, tubular damage, hemodynamic impairment and neuroendocrine activation to better define and classify the two syndromes on the basis of a specific cutoff analysis.

\section{Methods}

Study Design

Patients were enrolled consecutively from the Department of Internal Medicine, Cardiology Unit (Siena, Italy) from May 2010 to September 2012. They were eligible if they were admitted with a primary diagnosis of acute decompensated $\mathrm{HF}$, could be randomized $<24 \mathrm{~h}$ after hospital presentation and showed evidence of volume overload, pulmonary congestion on chest X-ray and B-type natriuretic peptide (BNP) levels $>100$ pg/ ml. We studied 246 consecutive patients affected by HF. They were divided into two groups based on estimated GFR (eGFR) and creatinine values of $50 \mathrm{ml} / \mathrm{min} / 1.73 \mathrm{~m}^{2}$ and $1.4 \mathrm{mg} / \mathrm{dl}$, respectively, on hospital admission. Patients with an eGFR $>50 \mathrm{ml} / \mathrm{min} / 1.73 \mathrm{~m}^{2}$ and a creatinine level $<1.4 \mathrm{mg} / \mathrm{dl}$ were defined as having HF without RI ( $\mathrm{n}=120)$; patients with an eGFR $<50 \mathrm{ml} / \mathrm{min} / 1.73 \mathrm{~m}^{2}$ and a creatinine level $>1.4 \mathrm{mg} /$ $\mathrm{dl}$ were defined as having CRS $(\mathrm{n}=126)$. This research was approved by our hospital's Institutional Review Board, and all patients gave their written informed consent on admission. 


\section{CardioRenal Medicine}

\begin{tabular}{l|l}
\hline \multicolumn{2}{l}{ Cardiorenal Med 2014;4:257-268 } \\
\hline DOI: 10.1159/000368375 & $\begin{array}{l}\text { C 2014 S. Karger AG, Basel } \\
\text { www.karger.com/crm }\end{array}$ \\
\hline
\end{tabular}

Palazzuoli et al.: Biomarkers of Cardiorenal Syndrome

\section{Exclusion Criteria}

Patients were excluded if they had end-stage renal disease or needed a renal replacement therapy (dialysis or ultrafiltration). Those with isolated diastolic dysfunction or recent myocardial infarction were also excluded as were those with a systolic blood pressure $<90 \mathrm{~mm} \mathrm{Hg}$ or a serum creatinine level $>4.0 \mathrm{mg}$ / $\mathrm{dl}$ and those with sepsis, systemic inflammatory diseases, liver or neoplastic diseases.

\section{Laboratory Analysis}

Centralized analyses of creatinine, blood urea nitrogen (BUN), interleukin-6 (IL-6), tumor necrosis factor- $\alpha$ (TNF- $\alpha$ ), BNP, neutrophil gelatinase-associated lipocalin (NGAL), troponin T (TnT) and osteoprotegerin (OPG) were performed from blood samples taken at the same time within $48 \mathrm{~h}$ following admission. All laboratory analyses were performed by investigators blinded to the cardiorenal indices and clinical outcome data. Creatinine and urea were measured using an enzymatic and colorimetric method. Measurement of BUN was performed by photometry: the enzyme urease converts urea to ammonia and carbonic acid. For these products, which are proportional to the concentration of urea in the sample, the system checks the decrease in absorbance at $340 \mathrm{~mm}$ when ammonia reacts with $\alpha$-ketoglutaric acid (UREAL Cobas, Roche System). Measurement of creatinine was performed by the Jaffé reaction, in which creatinine is treated with an alkaline picrate solution to yield a red complex. The velocity of the color makeup is directly proportional to the creatinine concentration measured photometrically (CREJ2 Cobas, Roche System). Plasma BNP was measured with the Triage BNP Test (Biosite Inc., San Diego, Calif., USA); this test is an immunoassay in a single-use plastic cartridge that fluorescently labels monoclonal antibody against BNP labeled with a fluorescent dye for BNP. The BNP level in 12 healthy subjects did not exceed $80 \mathrm{pg} / \mathrm{ml}$. NGAL testing was also performed on the Triage platform using a standard commercially available assay (Triage Assay, Alere Inc., San Diego, Calif., USA); this test is an immunoassay in a single-use plastic cartridge that fluorescently labels monoclonal antibody against NGAL labeled with a fluorescent dye for NGAL. The lowest measureable NGAL concentration by this test is $15 \mathrm{ng} / \mathrm{ml}$. The NGAL level in 12 healthy subjects did not exceed $91 \mathrm{ng} / \mathrm{ml}$. The TnT level was measured with the Elecsys ${ }^{\circledR}$ TnT STAT assay (Roche Diagnostics GmbH, Mannheim, Germany); this test is a two-step sandwich immunoassay with streptavidin microparticles and electrochemiluminescence detection for the measurement of human TnT in serum or plasma. This measurement was performed by the previously described ECLIA method with lower sensitivity. The TNF- $\alpha$ level was measured with human TNF- $\alpha$ Instant ELISA (eBioscience Campus Vienna Biocenter 2, Vienna, Austria), an enzyme-linked immunosorbent assay for quantitative detection. The lowest measureable TNF- $\alpha$ concentration by this test is $1.65 \mathrm{pg} / \mathrm{ml}$. The TNF- $\alpha$ level in 12 healthy subjects did not exceed $3.25 \mathrm{pg} / \mathrm{ml}$. To measure IL-6, we used human IL-6 Instant ELISA (eBioscience Campus Vienna Biocenter 2), an enzyme-linked immunosorbent assay for quantitative detection. The lowest measureable IL- 6 concentration by this test is $0.92 \mathrm{pg} / \mathrm{ml}$. The IL-6 level in 12 healthy subjects did not exceed $4.05 \mathrm{pg} / \mathrm{ml}$. OPG was measured with an ELISA assay (Biomedica Gruppe, Vienna, Austria); it is an enzyme-linked immunosorbent assay for quantitative detection. An anti-human OPG monoclonal coating antibody is adsorbed onto microwells. The lowest measureable OPG concentration by this test is 0.14 $\mathrm{pmol} / \mathrm{l}$. The OPG level in 12 healthy subjects did not exceed $5.00 \mathrm{pmol} / \mathrm{ml}$. The eGFR was calculated using the MDRD (modification of diet in renal disease) equation [11].

\section{Endpoints}

The following aims were defined: (1) to evaluate the different biochemical patterns by measuring the circulating levels of IL-6, TNF- $\alpha$, OPG, TnT, NGAL and BNP in CRS and HF patients; (2) to establish a correlation between renal function, neurohormonal, inflammatory and myocardial damage biomarkers in all patients and in two subgroups in order to evaluate a possible link with renal dysfunction, and (3) to establish the diagnostic power of the significant biomarkers, we calculated the best discriminatory cutoff accuracy.

\section{Statistical Analysis}

Continuous variables are expressed as means \pm standard deviation and compared using the $t$ test for independent groups if normally distributed, and as medians and interquartile ranges if nonnormally distributed; the nonnormally distributed variables were log-transformed, analyzed with the $t$ test and recalculated with anti-logarithmic transformation. Normality was assessed by the Kolmogorov-Smirnov test. Analysis of variance was done by Levene's test, and if it was breached we used Welch's correction. Pearson's correlation coefficient was calculated to determine the relationship between biomarkers in patients with CRS and those with HF. Receiver operating characteristic (ROC) curve analysis was used to assess the ability of biomarkers (those significant in the first analysis) to detect CRS; the area under the curve (AUC) and the 
Palazzuoli et al.: Biomarkers of Cardiorenal Syndrome

Table 1. Baseline clinical therapeutic and risk factor characteristics in CRS patients and in HF patients without RI

\begin{tabular}{|c|c|c|c|}
\hline & $\begin{array}{l}\text { CRS } \\
(\mathrm{n}=126)\end{array}$ & $\begin{array}{l}\text { HF without RI } \\
(\mathrm{n}=120)\end{array}$ & $\mathrm{p}$ value \\
\hline Age $($ mean $\pm S D)$, years & $81 \pm 7$ & $78 \pm 9$ & 0.02 \\
\hline \multicolumn{4}{|l|}{ Sex } \\
\hline Female & 73 & 62 & n.s. \\
\hline Male & 53 & 58 & n.s. \\
\hline Baseline weight (mean $\pm \mathrm{SD}$ ), kg & $71 \pm 9$ & $69 \pm 10$ & n.s. \\
\hline Baseline creatinine (mean $\pm \mathrm{SD}$ ), mg/dl & $2.1 \pm 0.9$ & $1.0 \pm 0.3$ & $<0.001$ \\
\hline BUN (mean \pm SD), mg/dl & $123 \pm 54$ & $55 \pm 23$ & $<0.001$ \\
\hline eGFR (mean $\pm \mathrm{SD}), \mathrm{ml} / \mathrm{min} / 1.73 \mathrm{~m}^{2}$ & $29 \pm 11$ & $70 \pm 18$ & $<0.001$ \\
\hline \multirow{2}{*}{\multicolumn{4}{|c|}{ Signs of congestion }} \\
\hline & & & \\
\hline Elevated jugular venous pressure & 55 & 59 & n.s. \\
\hline Additive heart sound & 38 & 42 & n.s. \\
\hline Pheripheral edema & 99 & 75 & n.s. \\
\hline Pulmonary rales & 117 & 103 & n.s. \\
\hline \multicolumn{4}{|l|}{ Coronary risk factors, $\%$} \\
\hline Diabetes mellitus & 59 & 31 & n.s. \\
\hline Hypertension & 73 & 58 & n.s. \\
\hline Dyslipidemia & 59 & 43 & n.s. \\
\hline Previous coronary artery disease & 65 & 39 & n.s. \\
\hline Atrial fibrillation, \% & 36 & 28 & n.s. \\
\hline \multicolumn{3}{|l|}{ Previous therapy } & n.s. \\
\hline ACE inhibitors & 92 & 97 & n.s. \\
\hline$\beta$-Blockers & 68 & 74 & n.s. \\
\hline Nitrates & 38 & 32 & n.s. \\
\hline Diuretics & 125 & 118 & n.s. \\
\hline Angiotensin receptor blockers & 20 & 12 & n.s. \\
\hline Digoxin & 42 & 34 & n.s. \\
\hline Aldosterone antagonist & 25 & 28 & n.s. \\
\hline
\end{tabular}

confidence intervals (CI) were calculated with the Wilcoxon and Mann-Whitney tests. For the biomarkers that were significant in the ROC curve analysis, we found the best cutoff value to detect CRS within the 90th percentile in the HF patients. Finally, we tested the ability of these biomarkers to detect CRS, using a logistic regression analysis and considering all cutoff values found. All reported probability values were two-tailed, and a p value $<0.05$ was considered statistically significant. Statistical analysis was performed using the SPSS 20.0 statistical software package (SPSS Inc., Chicago, Ill., USA).

\section{Results}

\section{Pattern of Biomarkers in CRS and HF Patients without RI}

Among the 246 patients who met the inclusion criteria, 8 patients were excluded due to a lack of some laboratory parameters. The remaining patients were divided into two groups: the first group consisted of 118 patients with $\mathrm{HF}$ (GFR $\geq 50 \mathrm{ml} / \mathrm{min} / 1.73 \mathrm{~m}^{2}$ ) and the second group consisted of 120 patients with CRS (GFR $<50 \mathrm{ml} / \mathrm{min} / 1.73 \mathrm{~m}^{2}$ ) (table 1). The level of BNP was significantly higher in the CRS group compared with the HF group $(626.41 \mathrm{pg} / \mathrm{ml}$, CI 518.01-749.94 vs. $487.85 \mathrm{pg} / \mathrm{ml}, \mathrm{CI} 411.58-578.25$; $\mathrm{p}<0.05)$, as was that of IL-6 (9.58 pg/ $\mathrm{ml}, \mathrm{CI} 7.10-12.93$ vs. $5.93 \mathrm{pg} / \mathrm{ml}, \mathrm{CI} 3.97-8.85$; $\mathrm{p}<0.05)$, that of NGAL $(156.02 \mathrm{ng} / \mathrm{ml}, \mathrm{CI}$ $129.02-186.79$ vs. $89.12 \mathrm{ng} / \mathrm{ml}, \mathrm{CI} 72.24-109.95 ; \mathrm{p}<0.001)$ and that of TnT $(0.62 \mathrm{ng} / \mathrm{ml}, \mathrm{CI}$ 
Palazzuoli et al.: Biomarkers of Cardiorenal Syndrome

Table 2. Different patterns of BNP, TNF- $\alpha$, IL-6, OPG, NGAL, BUN, BUN/creatinine ratio and TnT on the basis of eGFR values

\begin{tabular}{lccc}
\hline & eGFR $<50 \mathrm{ml} / \mathrm{min} / 1.73 \mathrm{~m}^{2}$ & eGFR $\geq 50 \mathrm{ml} / \mathrm{min} / 1.73 \mathrm{~m}^{2}$ & $\mathrm{p}$ value \\
\hline BNP, $\mathrm{pg} / \mathrm{ml}$ & $626.41(518.01-749.94)$ & $487.85(411.58-578.25)$ & $\mathbf{0 . 0 5}$ \\
TNF- $\alpha, \mathrm{pg} / \mathrm{ml}$ & $5.10(4.57-5.75)$ & $4.66(4.01-5.36)$ & 0.29 \\
IL-6, $\mathrm{pg} / \mathrm{ml}$ & $9.58(7.10-12.93)$ & $5.93(3.97-8.85)$ & $\mathbf{0 . 0 5}$ \\
OPG, pmol/l & $10.70(9.02-12.55)$ & $10.28(8.93-11.82)$ & 0.76 \\
NGAL, ng/ml & $156.02(129.02-186.79)$ & $89.12(72.24-109.95)$ & $<\mathbf{0 . 0 0 1}$ \\
BUN, mg/dl & $108.85(98.49-120.30)$ & $50.91(46.99-55.70)$ & $<\mathbf{0 . 0 0 1}$ \\
BUN/creatinine & $86.05(75.3-96.8)$ & $43.16(37.6-48.7)$ & $<\mathbf{0 . 0 1}$ \\
TnT, ng/ml & $0.62(0.51-0.75)$ & $0.21(0.15-0.28)$ & $<\mathbf{0 0 1}$ \\
\hline
\end{tabular}

p values in bold are significant.

Fig. 1. Correlation of eGFR and BUN in CRS patients.

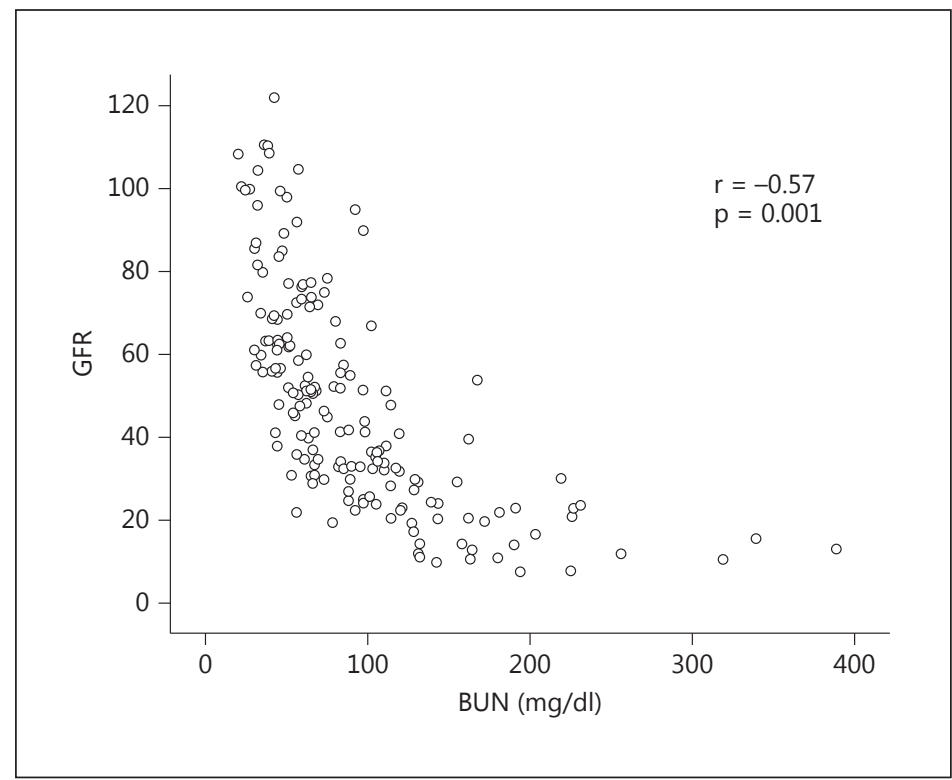

$0.51-0.75$ vs. $0.21 \mathrm{ng} / \mathrm{ml}, \mathrm{CI} 0.15-0.28 ; \mathrm{p}<0.001$ ). TNF- $\alpha$ and OPG demonstrated similar values in both groups. As expected, we found a significant increase in BUN $(108.85 \mathrm{mg} / \mathrm{dl}, \mathrm{CI}$ $98.49-120.30$ vs. $50.91 \mathrm{mg} / \mathrm{dl}, \mathrm{CI} 46.99-55.70 ; \mathrm{p}<0.001$ ) and the BUN/creatinine ratio (86.05, CI 75.3-96.8 vs. 43.16, CI 37.6-48.7; $\mathrm{p}<0.0001$ ) in the CRS group compared to the HF group (table 2).

\section{Correlation between GFR and Biomarkers}

In patients without RI, we observed a significant inverse correlation between GFR and TNF- $\alpha(r=-0.29 ; p=0.04)$ and between GFR and BUN $(r=-0.37 ; p=0.001)$. In the CRS group, we found a significant inverse correlation between GFR and BNP ( $r=-0.25 ; \mathrm{p}=0.005)$, BUN $(\mathrm{r}=-0.57 ; \mathrm{p}=0.001$; fig. 1$)$, TnT $(\mathrm{r}=-0.38 ; \mathrm{p}<0.001)$ and NGAL $(\mathrm{r}=-0.41 ; \mathrm{p}=0.02 ;$ table 3$)$. In patients without RI, correlation analysis showed a significant relationship between BNP and OPG $(\mathrm{r}=0.45 ; \mathrm{p}=0.001)$, BNP and NGAL $(\mathrm{r}=0.42 ; \mathrm{p}=0.03)$, BUN and TnT $(\mathrm{r}=0.41 ; \mathrm{p}=$ $0.001)$, TnT and OPG ( $r=0.33 ; p=0.05)$, IL-6 and BNP ( $r=0.34 ; p=0.005)$ and IL-6 and OPG 


\section{CardioRenal Medicine}

Table 3. Correlation between eGFR and all biomarkers in patients without RI and in CRS patients
Palazzuoli et al.: Biomarkers of Cardiorenal Syndrome

\begin{tabular}{llc}
\hline & eGFR & \\
\cline { 2 - 3 } & patients without RI & CRS patients \\
\hline BNP & -0.11 & $\mathbf{- 0 . 2 5}$ \\
TNF- $\alpha$ & $\mathbf{- 0 . 2 9}$ & 0.17 \\
IL-6 & -0.20 & -0.02 \\
OPG & -0.20 & -0.13 \\
NGAL & -0.04 & $\mathbf{- 0 . 4 1}$ \\
BUN & $\mathbf{- 0 . 3 7}$ & -0.57 \\
BUN/creatinine & -0.07 & -0.11 \\
TnT & -0.06 & $\mathbf{- 0 . 3 8}$
\end{tabular}

Figures in bold are significant correlations (Pearson's coefficient; $\mathrm{p}<0.05$ ).

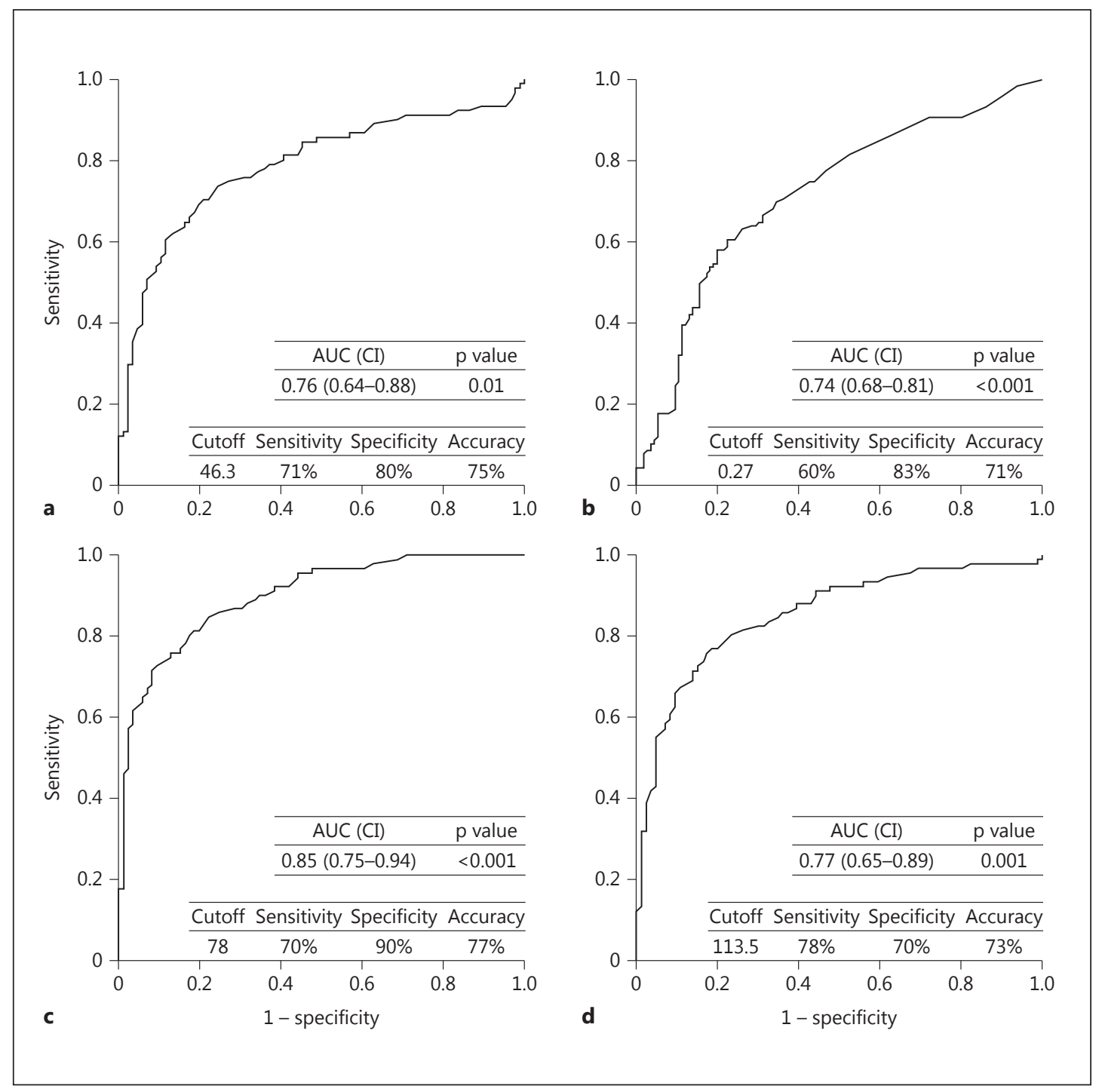

Fig. 2. ROC curve analysis showed that the BUN/creatinine ratio (a), TnT (b), BUN (c) and NGAL (d) could detect patients with CRS. 


\section{CardioRenal Medicine}

Table 4. Logistic regression analysis of significant laboratory biomarkers (considering cutoff values found)

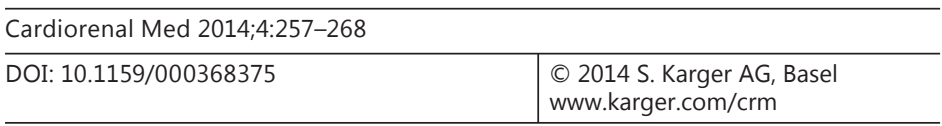

Palazzuoli et al.: Biomarkers of Cardiorenal Syndrome

\begin{tabular}{lll}
\hline & Odds ratio $(\mathrm{CI})$ & p value \\
\hline $\mathrm{NGAL} \geq 113.5 \mathrm{ng} / \mathrm{ml}$ & $2.73(1.53-5.92)$ & 0.01 \\
$\mathrm{BUN} \geq 78 \mathrm{mg} / \mathrm{dl}$ & $6.33(3.45-9.64)$ & 0.002 \\
$\mathrm{BUN} / \mathrm{creatinine} \geq 46.3$ & $5.47(2.91-8.52)$ & 0.001 \\
TnT $\geq 0.27 \mathrm{ng} / \mathrm{ml}$ & $2.31(1.24-4.71)$ & 0.583 \\
\hline
\end{tabular}

$(\mathrm{r}=0.43 ; \mathrm{p}=0.002)$. In CRS patients, there were significant relationships between BNP and creatinine ( $r=0.28 ; p=0.01)$, creatinine and NGAL ( $r=0.29 ; p=0.03)$, IL-6 and OPG ( $r=0.41$; $\mathrm{p}=0.001)$ and NGAL and BUN $(\mathrm{r}=0.50 ; \mathrm{p}=0.003)$.

\section{Accuracy of Biomarkers in the Identification of CRS}

The ROC curve analysis showed that cutoff levels of NGAL $>113.5 \mathrm{ng} / \mathrm{ml}$ can identify CRS patients with good accuracy (73\%; sensitivity $78 \%$ and specificity $70 \%$; $<<0.001$; AUC 0.77 , CI 0.65-0.89). The same analysis for TnT demonstrated that a cutoff level $>0.27 \mathrm{ng} / \mathrm{ml}$ had also a good accuracy (71\%; sensitivity $60 \%$ and specificity $83 \%$; $p<0.001$; AUC 0.74 , CI 0.68 0.81 ) to identify patients with CRS. In the same line, BUN levels $>78 \mathrm{mg} / \mathrm{dl}$ identified CRS patients with an accuracy of $77 \%$ (sensitivity $70 \%$ and specificity $90 \%$; $<<0.0001$; AUC 0.85 , CI 0.75-0.94). Moreover, a BUN/creatinine ratio $>46.3$ detected CRS patients with an accuracy of $75 \%$ (sensitivity $71 \%$ and specificity $80 \%$; p < 0.01; AUC 0.76 , CI $0.64-0.88$; fig. 2).

The logistic regression analysis showed that NGAL $\geq 113.5 \mathrm{ng} / \mathrm{dl}, \mathrm{BUN} \geq 78 \mathrm{mg} / \mathrm{dl}$ and a BUN/creatinine ratio $\geq 46.3$ were able to detect patients with CRS; in contrast, $\mathrm{TnT} \geq 0.27 \mathrm{ng}$ / $\mathrm{ml}$ was not significant in the assessment of patients with CRS (table 4).

\section{Discussion}

Acute and chronic HF has often been associated with an increased risk of kidney injury and damage. For instance, cardiovascular diseases account for $>50 \%$ of adverse events in patients with RI [12]. In the most recent European and American guidelines for HF management, renal dysfunction is considered an index of poor prognosis regardless of the presence of other traditionally investigated risk factors. However, the mechanisms by which the onset of acute or chronic HF lead to RI are multiple and complex [13]. The pathophysiology of acute kidney injury (AKI) during acute HF (CRS subtype 1) is poorly understood, and it likely involves interrelated hemodynamic and neurohormonal mechanisms that could contribute to worse cardiovascular outcomes in these patients. In HF and coexistent CKD, other mechanisms have been proposed to explain the poor outcome. These include accelerated hypertension, left ventricular hypertrophy, increased activation of the renin-angiotensin system, reduced renal perfusion, diuretic resistance and volume overload secondary to difficulties with sodium excretion [5, 6, 14]. In both acute and chronic HF, the worsening of renal function is not only due to kidney hypoperfusion and renal blood flow redistribution, but also to several autocrine and paracrine systems increased in relation to a primitive hemodynamic dysfunction [15]. For these reasons, the definition of a laboratory pattern able to identify this endocrine overdrive early could help to timely diagnose and understand the pathophysiological mechanisms involved. In this sense, CRS subtypes 1 and 2 have recently been defined emphasizing the complex pathophysiological liaison linking the heart and the kidney [4]. Although CRS is considered a new well-recognized disease, it lacks definitive cutoff values regarding specific RI parameters as well as a specific laboratory pattern able to better identify the syndrome. Therefore, since 5 subtypes of CRS 
Palazzuoli et al.: Biomarkers of Cardiorenal Syndrome

have been defined, establishing laboratory tools that are able to identify primitive and secondary organ damage appears mandatory.

CRS subtypes 1 and 2 have common pathophysiological mechanisms due to primary systo-diastolic dysfunction followed by an activation of the renin-angiotensin system, sympathetic activation, increased venous pressure leading to a derangement in the intraglomerular blood flow and increased sodium and water reabsorption. A mixed model including both forward and backward HF with right-side dysfunction, augmented renal venous pressure, kidney congestion, tubule obliteration and renal hypoxic damage is currently deemed the most appropriate liaison [16], particularly in the acute subtypes. For all these accounts, we studied several biomarkers able to distinguish between patients with CRS subtypes 1 and 2 and patients with acute and chronic HF without RI.

The findings of the current study can be summarized in three main points: (1) our data demonstrate that, beyond the traditional laboratory parameters consisting in creatinine and GFR measurement, some others laboratory markers could help in the identification of patients with CRS; (2) some specific renal and extrarenal biomarkers (i.e. NGAL, TnT and BUN) above certain cutoff values appear to be able to identify patients with HF and associated RI, whereas other common biomarkers employed in the diagnosis and monitoring of HF (such as BNP), are not able to discriminate patients with or without CRS, and (3) biomarkers able to identify patients with CRS are not directly correlated with kidney damage but appear to be increased in relation to a more intense neurohormonal activity (i.e. BUN and TnT).

There are several reasons why the evaluation of renal function during HF appears to be mandatory: the clinical impact of RI on cardiovascular diseases, the high prevalence of this condition in HF patients and the need to make an early diagnosis. Unfortunately, the common laboratory parameters used in clinical practice for RI diagnosis are not sensitive enough for AKI recognition: even the RIFLE criteria reflect late kidney damage with a loss of nephrons above one third. Therefore, neither creatinine nor GFR can identify the type of renal dysfunction (renal or prerenal) due to glomerular or tubular insult [17]. Serum creatinine is primarily a marker of glomerular filtration. It is insensitive and unreliable in the diagnosis of renal tubular injury in the absence of a significant reduction in GFR. Its concentration increases only after half of the kidney function has been lost, which may be days after the renal insult. On the other hand, GFR is prone to several biases linked to the formula used for its calculation (age, body weight and patient setting). The recognition of biomarkers for the early diagnosis of kidney injury is now becoming a research priority [18].

Our data demonstrated that BNP, BUN, the BUN/creatinine ratio, IL-6, NGAL and TnT are all increased in patients with renal dysfunction compared to patients with a preserved renal function; nevertheless, only BUN, NGAL and TnT are able to identify patients with CRS according to the ROC analysis. Whereas NGAL is a biomarker of primitive renal tubular damage, BUN and TnT could be simply a 'mirror' of kidney dysfunction.

Natriuretic peptides (NP) are hormones secreted by the ventricles and the atriums, and their circulating concentrations are elevated in patients with chronic or acute HF. Increased levels of metabolism and excretion modality also depend on renal function. Each NP increases in relation to AKI severity. For these reasons, NP have the potential to serve as a valuable diagnostic and prognostic tool in several CRS types. Patients with CKD have higher levels of NP than normal subjects although this is attributed to reduced renal clearance. However, not all studies agree on this assumption, because NP concentrations could potentially depend on several variables such as left ventricular hypertrophy, myocardial stress, inflammatory status, age and body weight. In advanced CKD stages, the mean increase is around one third with respect to subjects with preserved renal function $[16,19,20]$. In our study, BNP appears to be increased in CRS, but compared with confounding factors it has not been shown to be a sensitive tool for CRS diagnosis. 


\section{CardioRenal Medicine}

Palazzuoli et al.: Biomarkers of Cardiorenal Syndrome

BUN is currently considered to be a devoted marker of endocrine overdrive. In fact, urea metabolism depends on three variables: (1) BUN concentration at the proximal tubule, which is related to systemic urea production; (2) urea velocity and reabsorption at the distal tubule, and (3) urea transport and concentration in the inner medulla. All of these processes are modulated by RAA, the arginine vasopressin system and sympathetic nervous system [21]. Because BUN should be considered a marker of neurohormonal activation, it is not surprising that even the BUN/creatinine ratio is elevated in our patients. The BUN/creatinine ratio is currently considered a useful diagnostic tool for identifying patients with adverse outcome and reduced GFR. It is assumed to be a surrogate marker for renal dysfunction as well as for neurohormonal activation and sympathetic overdrive due to primitive HF [22].

On the other hand, it has been argued that circulating troponin levels are commonly elevated in patients with impaired renal function in the absence of an acute coronary syndrome [23-25]. Although high levels have been observed in the setting of even minor degrees of renal dysfunction, they remain associated with cardiovascular events across a whole spectrum of RI. More recently, an analysis of the PREVEND study (prevention of renal and vascular end-stage disease), a large prospective cohort study investigating the natural course of albuminuria and its relation to renal and cardiovascular disease, has shown that highly sensitive TnT levels were independently associated with eGFR and urinary albumin excretion [26]. Potential mechanisms to explain the association between RI and myocardial injury with elevated troponin levels include both cardiac injury and decreased renal clearance. A causal link between RI and cardiac dysfunction may involve the fibroblast growth factor-23, a hormone that controls phosphorus homeostasis. Fibroblast growth factor- 23 is upregulated and directly provokes left ventricular hypertrophy in experimental models of CKD $[27,28]$. Therefore, TnT is increased because of suddenly increased wall stress, altered calcium handling, inflammatory activation and reduced degradation. However, the precise molecular mechanisms responsible for troponin release are not perfectly understood. Experimental data suggest that necrotic, and perhaps apoptotic, myocytes lose the sarcolemma integrity becoming permeable to troponin molecules $[16,29,30]$.

The clinical use of serum NGAL levels in patients admitted to the hospital for acute decompensated HF (ADHF) to estimate the risk of early worsening renal function (WRF) has recently been proposed. NGAL is produced by the nephron in response to tubular epithelial damage and is considered an early marker for acute renal tubular injury in several clinical settings $[31,32]$. Data from the GISSI-HF trial confirmed that urinary NGAL is a good index of tubular damage and is significantly increased in patients with chronic HF and preserved renal function. High levels are also related to poor outcome in a long follow-up period [33]. Considering 91 patients admitted to the hospital with ADHF, Aghel et al. [34] showed that those who developed WRF during hospitalization had significantly higher median levels of serum NGAL on admission. They observed that patients with admission NGAL values $\geq 140 \mathrm{ng} / \mathrm{ml}$ had a 7.4-fold increased risk of developing WRF. Recently, the GALLANT prospective trial has shown that plasma NGAL is a good prognostic biomarker of early poor outcome in patients with ADHF [35]. Similar results were found by Alvelos et al. [36] in a 3-month follow-up period and by Palazzuoli et al. [37] in a 6-month follow-up period. In line with the current reports, we found a significant increase in NGAL level in CRS patients as well as a significant correlation with eGFR in the same group. In contrast, in patients with HF without RI, no correlation between the NGAL level and eGFR was found, thus confirming the role of NGAL as a specific tubular damage marker. Despite these positive findings, more recently, the role of NGAL in detecting tubular damage and AKI during ADHF has been questioned [38].

Our findings demonstrated this neurohormonal overdrive, emphasizing the importance of endocrine system activation in CRS pathogenesis and diagnosis. In this context, the study of laboratory tools able to recognize both renal and cardiac damage appears mandatory [39]. In addition, serial biomarker measurements are becoming surrogate endpoints to identify 
Palazzuoli et al.: Biomarkers of Cardiorenal Syndrome

responder patients and the safety of new drugs [40]. BUN, NGAL and TnT could reflect hemodynamic stress, kidney and cardiac damage, respectively. Measurement of traditional and new laboratory parameters might allow an early detection of kidney injury and the recognition of its underlying mechanism.

\section{Limitations}

Since this was a single-center observational study, it is prone to several forms of bias due to the nature of the protocol: the first limitation is the small sample size of the population we studied; secondly, RI of the enrolled patients could have different pathophysiological mechanisms and timing (i.e. WRF, CKD, and AKI).

By our analysis, it was not possible to distinguish subtypes. Along the same line, the primary etiology of RI was not exactly defined because our patients did not undergo renal biopsy. However, all patients had a similar heart disease, and they could all be classified into CRS subtypes 1 and 2. Moreover, it is the first study to analyze this biomarker pattern in this field. We proposed an arbitrary cutoff for the definition of CRS (eGFR $<50 \mathrm{ml} / \mathrm{min} / 1.73 \mathrm{~m}^{2}$ ), although the universal cutoff for mild RI was higher (eGFR $<60 \mathrm{ml} / \mathrm{min} / 1.73 \mathrm{~m}^{2}$ ). So far, no standardized cutoff for CRS patients has been defined yet. Moreover, our patients had several comorbidities and advanced age. Finally, considering the clinical characteristics of our population (diabetic, hypertensive, mean age around 80 years) and the high atherosclerotic burden, an eGFR cutoff $>50 \mathrm{ml} / \mathrm{min} / 1.73 \mathrm{~m}^{2}$ should reflect a satisfying renal function. We only included basal renal function on admission without comparing our laboratory results with the trend in renal function during the observation period. The current study did not provide any follow-up data but only a biochemical characterization. To establish the exact importance and clinical impact of these findings, a temporal evaluation of these patients appears mandatory. Finally, the accuracy of the cutoff values established in our report needs to be confirmed in a further larger population with the same clinical conditions.

\section{Conclusions}

Although CRS is considered a well-recognized disease, it lacks specific laboratory patterns and definitive cutoff values. Our data suggest that HF patients who displayed a moderate kidney dysfunction had a significant increase in renal tubular (NGAL) and systemic biomarkers (BUN and TnT) compared to HF patients without RI. These biomarker patterns could be used for an early diagnosis of RI in patients with acute and chronic HF. The more intense neurohormonal and hemodynamic overdrive together with increased renal tubular damage could potentially explain the adverse outcome in CRS patients.

\section{Acknowledgements}

We are grateful to: Alere, Biosite Inc. (San Diego, Calif., USA) for supplying the BNP and NGAL assay kits used in this study; Biomedica Gruppe (Vienna, Austria) for supplying the OPG assay kits used in this study; Roche Diagnostics GmbH (Mannheim, Germany) for supplying the creatinine, BUN and TnT kits used in this study, and eBioscience (Campus Vienna Biocenter 2, Vienna, Austria) for supplying the IL-6 and TNF- $\alpha$ assay kits used in this study.

\section{Disclosure Statement}

The authors declare that there are no conflicts of interest. 


\section{CardioRenal Medicine}

\begin{tabular}{l|l}
\hline \multicolumn{2}{l}{ Cardiorenal Med 2014:4:257-268 } \\
\hline DOI: $10.1159 / 000368375$ & $\begin{array}{l}\text { C 2014 S. Karger AG, Basel } \\
\text { www.karger.com/crm }\end{array}$ \\
\hline
\end{tabular}

Palazzuoli et al.: Biomarkers of Cardiorenal Syndrome

\section{References}

1 Smith GL, Lichtman JH, Bracken MB, Shlipak MG, Phillips CO, DiCapua P, Krumholz HM: Renal impairment and outcomes in heart failure: systematic review and meta-analysis. J Am Coll Cardiol 2006;47:1987-1996.

-2 Heywood JT, Fonarow GC, Costanzo MR, Mathur VS, Wigneswaran JR, Wynne J: High prevalence of renal dysfunction and its impact on outcome in 118,465 patients hospitalized with acute decompensated heart failure: a report from the ADHERE Database. J Card Fail 2007;13:422-430.

-3 Klein L, Massie BM, Leimberger JD O’Connor CM, Piña IL, Adams KF Jr, Califf RM, Gheorghiade M: Admission or changes in renal function during hospitalization for worsening heart failure predict post discharge survival. Cir Heart Fail 2008;1:25-33.

4 House AA, Anand I, Bellomo R, Cruz D, Bobek I, Anker SD, Aspromonte N, Bagshaw S, Berl T, Daliento L, Davenport A, Haapio M, Hillege H, McCullough P, Katz N, Maisel A, Mankad S, Zanco P, Mebazaa A, Palazzuoli A, Ronco F, Shaw A, Sheinfeld G, Soni S, Vescovo G, Zamperetti N, Ponikowski P, Ronco C; Acute Dialysis Quality Initiative Consensus Group: Definition and classification of Cardio-Renal Syndromes: workgroup statements from the 7th ADQI Consensus Conference. Nephrol Dial Transplant 2010;25:1416-1420.

5 Packer M: The neurohormonal hypothesis: a theory to explain heart disease progression in heart failure. J Am Coll Cardiol 1992;20:248-254.

6 Schrier RW: Role of diminished renal function in cardiovascular mortality: marker or pathogenetic factor? J Am Coll Cardiol 2006;47:1-8.

7 Vittorini S, Clerico A: Cardiovascular biomarkers: increasing impact of laboratory medicine in cardiology practice. Clin Chem Lab Med 2008;46:748-763.

8 Maisel AS, Katz N, Hillege HL, Shaw A, Zanco P, Bellomo R, Anand I, Anker SD, Aspromonte N, Bagshaw SM, Berl T, Bobek I, Cruz DN, Daliento L, Davenport A, Haapio M, House AA, Mankad S, McCullough P, Mebazaa A, Palazzuoli A, Ponikowski P, Ronco F, Sheinfeld G, Soni S, Vescovo G, Zamperetti N, Ronco C; Acute Dialysis Quality Initiative consensus group: biomarkers in kidney and heart disease. Nephrol Dial Transplant 2011;26: 62-74.

-9 McCullough PA, Bouchard J, Waikar SS, Siew ED, Endre ZH, Goldstein SL, Koyner JL, Macedo E, Doi K, Di Somma S, Lewington A, Thadhani R, Chakravarthi R, Ice C, Okusa MD, Duranteau J, Doran P, Yang L, Jaber BL, Meehan S, Kellum JA, Haase M, Murray PT, Cruz D, Maisel A, Bagshaw SM, Chawla LS, Mehta RL, Shaw AD, Ronco C: Implementation of novel biomarkers in the diagnosis, prognosis, and management of acute kidney injury: executive summary from the tenth consensus conference of the Acute Dialysis Quality Initiative (ADQI). Contrib Nephrol 2013;182:5-12.

10 National Kidney Foundation: K/DOQI clinical practice guidelines for chronic kidney disease: evaluation, classification, and stratification. Am J Kidney Dis 2002;39:S1-S266.

$>11$ Levey AS, Coresh J, Greene T, Stevens LA, Zhang YL, Hendriksen S, Kusek JW, Van Lente F; Chronic Kidney Disease Epidemiology Collaboration: Using standardized serum creatinine values in the modification of diet in renal disease study equation for estimating glomerular filtration rate. Ann Intern Med 2006;145:247-254.

12 Bagshaw SM, Cruz DN, Aspromonte N, Daliento L, Ronco F, Sheinfeld G, Anker SD Anand I, Bellomo R, Berl T, Bobek I, Davenport A, Haapio M, Hillege H, House A, Katz N, Maisel A, Mankad S, McCullough P, Mebazaa A, Palazzuoli A, Ponikowski P, Shaw A, Soni S, Vescovo G, Zamperetti N, Zanco P, Ronco C; for the Acute Dialysis Quality Initiative (ADQI) Consensus Group: Epidemiology of cardio-renal syndromes: workgroup statements from the 7th ADQI Consensus Conference. Nephrol Dial Transplant 2010;25:1406-1416.

-13 Jessup M, Abraham WT, Casey DE, Feldman AM, Francis GS, Ganiats TG, Konstam MA, Mancini DM, Rahko PS, Silver MA, Stevenson LW, Yancy CW: 2009 Focused update. ACCF/AHA Guidelines for the Diagnosis and Management of Heart Failure in Adults: a report of the American College of Cardiology Foundation/American Heart Association Task Force on practice guidelines: developed in collaboration with the International Society for Heart and Lung Transplantation. Circulation 2009;119:1977-2016.

14 Metra M, Dei Cas L, Bristow MR: The pathophysiology of acute heart failure it is a lot about fluid accumulation. Am Heart J 2008;155:1-5.

15 Damman K, Navis G, Voors AA, Asselbergs FW, Smilde TD, Cleland JG, van Veldhuisen DJ, Hillege HL: Worsening renal function and prognosis in heart failure: systematic review and meta-analysis. J Card Fail 2007;13:599608.

16 Palazzuoli A, Masson S, Ronco C, Maisel A: Clinical relevance of biomarkers in heart failure and cardiorenal syndrome: the role of natriuretic peptides and troponin. Heart Fail Rev 2014;19:267-284.

17 Soni SS, Ronco C, Katz N, Cruz DN: Early diagnosis of acute kidney injury: the promise of novel biomarkers. Blood Purif 2009;28:165-174.

18 Cruz D, Goh CY, Palazzuoli A, Slavin L, Calabrò A, Ronco C, Maisel A: Laboratory parameters of cardiac and kidney dysfunction in cardio-renal syndromes. Heart Fail Rev 2011;16:545-551.

19 Vesely DL: Natriuretic peptides and acute renal failure. Am J Physiol Renal Physiol 2003;285:F167-F177.

20 Vesely DL: Discovery of new cardiovascular hormones for the treatment of congestive heart failure. Cardiovasc Hematol Disord Drug Targets 2007;7:47-62.

-21 Kazory A: Emergence of blood urea nitrogen as a biomarker of neurohormonal activation in heart failure. Am J Cardiol 2010;106:694-700. 


\section{CardioRenal Medicine}

Palazzuoli et al.: Biomarkers of Cardiorenal Syndrome

-22 Brisco MA, Coca SG, Chen J, Owens AT, McCauley BD, Kimmel SE, Testani JM: Blood urea nitrogen/creatinine ratio identifies a high-risk but potentially reversible form of renal dysfunction in patients with decompensated heart failure. Circ Heart Fail 2013;6:233-239.

23 Lamb EJ, Kenny C, Abbas NA, John RI, Webb MC, Price CP, Vickery S: Cardiac troponin I concentration is commonly increased in nondialysis patients with CKD: experience with a sensitive assay. Am J Kidney Dis 2007;49:507-716.

24 Abbas NA, John RI, Webb MC, Kempson ME, Potter AN, Price CP, Vickery S, Lamb EJ: Cardiac troponins and renal function in nondialysis patients with chronic kidney disease. Clin Chem 2005;51:2059-2066.

25 Freda BJ, Tang WH, Van Lente F, Peacock WF, Francis GS: Cardiac troponins in renal insufficiency: review and clinical implications. J Am Coll Cardiol 2002;40:2065-2071.

-26 Scheven L, de Jong PE, Hillege HL, Lambers Heerspink HJ, van Pelt LJ, Kootstra JE, Bakker SJ, Gansevoort RT; for the PREVEND study group: High-sensitive troponin T and N-terminal pro-B type natriuretic peptide are associated with cardiovascular events despite the cross-sectional association with albuminuria and glomerular filtration rate. Eur Heart J 2012;33:2272-2281.

27 Ix JH, Katz R, Kestenbaum BR, de Boer IH, Chonchol M, Mukamal KJ, Rifkin D, Siscovick DS, Sarnak MJ, Shlipak MG: Fibroblast growth factor-23 and death, heart failure, and cardiovascular events in community-living individuals: CHS (Cardiovascular Health Study). J Am Coll Cardiol 2012;60:200-207.

-28 Negishi K, Kobayashi M, Ochiai I, Yamazaki Y, Hasegawa H, Yamashita T, Shimizu T, Kasama S, Kurabayashi M: Association between fibroblast growth factor 23 and left ventricular hypertrophy in maintenance hemodialysis patients. Comparison with B-type natriuretic peptide and cardiac troponin T. Circ J 2012;74:27342740.

29 Kociol RD, Pang PS, Gheorghiade M, Fonarow GC, O'Connor CM, Felker GM: Troponin elevation in heart failure prevalence, mechanisms, and clinical implications. J Am Coll Cardiol 2010;56:1071-1078.

30 Agewall S, Giannitsis E, Jernberg T, Katus H: Troponin elevation in coronary vs non-coronary disease. Eur Heart J 2011;32:404-411.

31 Wagener G, Gubitosa G, Wang S, Borregaard N, Kim M, Lee HT: Urinary neutrophil gelatinase-associated lipocalin and acute kidney injury after cardiac surgery. Am J Kidney Dis. 2008;52:425-433.

-32 Yndestad A, Landrø L, Ueland T, Dahl CP, Flo TH, Vinge LE, Espevik T, Frøland SS, Husberg C, Christensen G, Dickstein K, Kjekshus J, Øie E, Gullestad L, Aukrust P: Increased systemic and myocardial expression of neutrophil gelatinase-associated lipocalin in clinical and experimental heart failure. Eur Heart J 2009;30: 1229-1236.

-33 Damman K, Masson S, Hillege HL, Maggioni AP, Voor AA, Opasich C, van Veldhuisen DJ, Montagna L, Cosmi F, Tognoni G, Tavazzi L, Latini R: Clinical outcome of renal tubular damage in chronic heart failure. Eur Heart J 2011;32:2705-2712.

-34 Aghel A, Shrestha K, Mullens W, Borowski A, Tang WH: Serum neutrophil gelatinase-associated lipocalin (NGAL) in predicting worsening renal function in acute decompensated heart failure. J Card Fail 2010;16: 49-54.

35 Maisel A, Mueller C, Fitzgerald R, Brikhan R, Hiestand BC, Iqbal N, Clopton P, van Veldhuisen DJ: Prognostic utility of plasma neutrophil gelatinase-associated lipocalin in patients with acute heart failure the NGAL evaluation along B-type natriuretic peptide in acutely decompensated heart failure (GALLANT) trial. Eur J Heart Fail 2011;13:846-851.

-36 Alvelos M, Lourenco P, Dias C, Amorim M, Rema J, Leite AB, Guimaraes JT, Almeida P, Bettencourt P: Prognostic value of neutrophil gelatinase-associated lipocalin in acute heart failure. Int J Cardiol 2013;165:51-55.

-37 Palazzuoli A, Ruocco G, Beltrami M, Franci B, Pellegrini M, Lucani B, Nuti R, Ronco C: Admission plasma neutrophil gelatinase associated lipocalin (NGAL) predicts worsening renal function during hospitalization and post discharge outcome in patients with acute heart failure. Acute Card Care 2014;16:93-101.

-38 Breidthardt T, Socrates T, Drexler B, Noveanu M, Heinisch C, Arenja N, Klima T, Züsli C, Reichlin T, Potocki M, Twerenbold R, Steiger J, Mueller C: Plasma neutrophil gelatinase-associated lipocalin for the prediction of acute kidney injury in acute heart failure. Crit Care 2012;16:R2.

-39 Palazzuoli A, Beltrami M, Pellegrini M, Nuti R: Natriuretic peptides and NGAL in heart failure: does a link exist? Clin Chim Acta 2012;413:1832-1838.

40 Felker MG: Biomarkers as a surrogate end points in heart failure trials. Heart Fail Clin 2011;7:501-507. 